\title{
PRESIDENTIAL ADDRESS TO THE 48th CONFERENCE 1995
}

\section{A. RAHMAN}

It is with great pleasure that I present this 1994/95 report to our members. This has been another very satisfying and stimulating year for our Society. We have made significant progress on many issues and are delighted with the outcomes.

Following on from the success of the 1993 Symposium, we undertook to hold our second Symposium along with this year's Conference. A considerable amount of work was done over the past 12 months resulting in an excellent Symposium on Pesticide Resistance which most of us attended two days ago. It was very time consuming to organise and no doubt the work will continue for some months yet to prepare the publication resulting from the Symposium. We are indebted to all those involved in organising this successful event.

The 50th Anniversary of our Society is not too far away and we have discussed plans during the year to host some special events for this milestone in the history of our Society. We have contacted some relevant scientific societies in New Zealand and Australia to investigate possibilities of their active participation or even holding a joint conference. We are also working on a new book on weeds/wild flowers of New Zealand with the hope of launching it at the 50th Conference.

As an affiliated member of the Royal Society of New Zealand, our Society has made significant contributions in scientific matters of interest to the progress and well-being of its members. We are represented on two relevant committees of the Royal Society. The standing Committee on Primary Production Sciences and Technologies has made several submissions on policies related to research priorities and funding of agricultural, horticultural and arable cropping sectors. The Standing Committee on the Science of the New Zealand Environment has been active with issues relating to the Sustainable Land Management Strategy and the Environment 2010 Strategy. Our Society has made its own submission on some of these issues, but the two Committees give us another vehicle to enhance our communication with the politicians and decision makers whose deliberations often impact heavily on working life of our members.

Our Scientific Editor, Alison Popay, has worked hard to produce another large Proceedings of excellent scientific quality. The large number of papers offered and the number of people that have registered for both the Symposium and the Conference speaks well for our Society in this age of declining membership and decreasing levels of voluntary contributions. Alison has decided to vacate the position of Editor after ten years in this role. The quality and presentation of our Proceedings has improved steadily over these ten years and we are all grateful to Alison for the dedicated and hard work. Her name is being proposed for life membership by the Executive Committee at this AGM as a recognition of her dedication. We are indebted to Dr Maureen O'Callaghan who has willingly volunteered to take over as the Scientific Editor of our Society.

We were extremely grieved to hear of the sad death of the well known and well respected weed scientist, Frank Allan. Although retired from his regular employment, he was still active in our Society in many ways. Frank made many significant contributions over the years and was elected a life member of the Society back in 1976. An obituary will appear in next year's Proceedings.

The value of any scientific Society relates directly to the contributions made by its members. I urge you to continue your full and active support to help your Society achieve its prime objective of pooling and exchanging information related to Plant Protection. Finally, as we are all aware, no Society can thrive as well as ours does, without a committed Executive. All Committee members have freely given their time and energy in professionally executing tasks for the Society. As I finish my two year term as President of the Society, I would like to thank them all on my behalf, and on 